\title{
LA ANTROPOLOGÍA DENTRO DE LA FORMACIÓN HUMANÍSTICA*
}

Diego Prieto Hernández**

RECEPCIÓN: 30 de mayo de 2018.

APROBACIÓN: 5 de marzo de 2020.

DoI: $10.5347 / 01856383.0133 .000299231$

\section{Introducción}

El otro día, el doctor José Regueiro me preguntaba si la antropología era una ciencia y, en verdad, le contesté que, a estas alturas, no podía decir si es o no una ciencia. Se dice que lo es, pero lo que sí me queda claro es que se trata de un estado de ánimo. Yo diría que se trata de un estado de ánimo que tiene que ver fundamentalmente con la construcción intelectual de la experiencia del otro. Es decir, la antropología regresa permanentemente a reflexionar sobre el otro y por eso alguna vez que hablaba acerca de esto, iniciaba, como hoy lo hago, con una pequeña cita de Piedra de sol de Octavio Paz, que no es antropólogo, pero en esa parte sin duda coincide con lo que yo consideraría el espíritu antropológico o, dicho de otra manera, con el espíritu etnográfico. Más adelante hablaré sobre qué es la etnografía. Paz dice:

\footnotetext{
Para que pueda ser he de ser otro, salir de mí, buscarme entre los otros, los otros que no son si yo no existo, los otros que me dan plena existencia,
}

* Conferencia impartida en el ITAm el 30 de mayo de 2018.

** Director General del Instituto Nacional de Antropología e Historia. 
no soy, no hay yo, siempre somos nosotros, la vida es otra, siempre allá, más lejos, fuera de ti, de mí, siempre horizonte, vida que nos desvive y enajena.

\section{Surgimiento y objetivo de la antropología}

La antropología surgió como programa de investigación de los grupos humanos, con la idea de que es parte del amplio campo que desde el siglo XIX se llama ciencias sociales. Dice Immanuel Wallerstein que la Revolución Francesa, el gran acontecimiento cultural, social, histórico e intelectual de la modernidad occidental, produce tres grandes entidades que emergen en el siglo XIX: primero, los partidos políticos, segundo, los movimientos sociales y por último, las ciencias sociales. ${ }^{1}$ También nos dice que la Revolución Francesa inculcó a Occidente la convicción de la normalidad del cambio, es decir, Occidente descubrió que se pueden cambiar las formas de vivir, de organizar la sociedad y de transformar al régimen político. Descubrió que hasta se le puede cortar la cabeza al rey y no sucede mucho. Y eso que entonces se creía

116 que el rey era una representación divina, una representación de Dios y del mundo. Sobre esto hay muchas reflexiones en las que no quisiera ahondar, pero quiero plantear que, efectivamente, en el siglo XIX (aunque antes ya se había desarrollado un poco la economía con los fisiócratas) se empezó a configurar todo este mundo que llamamos las ciencias sociales: la sociología, la ciencia política, la economía y, más tarde, la psicología social.

Wallerstein se pregunta qué papel desempeña la antropología, porque las otras ciencias tienen que ver con el conocimiento de Occidente por el propio Occidente. La sociología está preocupada fundamentalmente por conocer cómo opera la sociedad moderna, la sociedad industrial, lo mismo que la economía. La ciencia política aspira a entender cómo operan los Estados nacionales y los regímenes políticos modernos. Y

${ }^{1}$ Immanuel Wallerstein, El moderno sistema mundial, IV, 2011, México, Siglo XXI, trad. de Victoria Schussheim. 
a la antropología se le deja la tarea de estudiar todas estas sociedades que no entienden la normalidad del cambio, todas estas sociedades que no están todavía insertas en lo que la idea clásica llama historia. La historia pensada como el registro consciente del devenir de los pueblos. Hay una serie de sociedades que justamente son las que Occidente ocupa, coloniza, domina, y que no están insertas en esta manera de entender la historia, el mundo, el cambio, la sociedad, el Estado. Por eso, Wallerstein dice que a esta disciplina o ciencia se le va a atribuir la tarea de introducir estas sociedades en el cambio, en la normalidad del cambio; es decir, se trata de incorporarlas en este mundo global que se viene armando desde el siglo XVI. Pero ya en el siglo XIX este mundo está claramente perfilado - diría Wallerstein - como un sistema-mundo y, gracias a la antropología, se explica cómo son estas sociedades y cómo se van a insertar en ese sistema-mundo; cómo se van a incorporar a la modernidad, cómo se van a introducir en una idea de sociedad que se asume inscrita en una historia que tiene finalidades, porque no todas las sociedades piensan que haya una finalidad. Vamos a incorporar a estas sociedades a una idea de un mundo donde existe un devenir, un sentido, una finalidad. Por eso hablamos de historia, y esta finalidad fundamentalmente es lo que Occidente llama progreso. En síntesis, se trata de incorporar a todos estos grupos humanos, a estas sociedades, al progreso. Ya ustedes sabrán, porque son historiadores, lo que esto significó en concreto.

La antropología, desde su inauguración, desde sus inicios, busca explicar la diversidad humana: cómo es que los seres humanos pueden ser diferentes física, lingüística, socialmente, cómo es que los seres humanos podemos ser tan diversos. Obviamente, el impacto con la diversidad es muy propio del ser humano. Tanto de la diversidad fenotípica, de cómo nos vemos, cuanto de la diversidad cultural. De niño a mí me llamaba mucho la atención cuando me enteraba de que había gente que comía de otra manera, que saludaba de otra manera, que formaba su familia de otra manera. Diría que la antropología surgió con tres preguntas fundacionales que le dan sentido desde el principio: la pregunta precisamente sobre la diversidad humana, la pregunta sobre 
el origen de los grupos humanos, de la propia especie humana, y la pregunta sobre la naturaleza del ser humano: ¿qué es? Si somos tan diferentes, ¿qué es lo que nos hace ser iguales, parecidos o, finalmente, seres humanos? Es la pregunta básica del humanismo; por eso, la antropología es una suerte de heredera, ahora en versión cientificista, del humanismo que viene desde el Renacimiento y que se pregunta sobre el ser humano.

La antropología se pregunta también qué es lo que hace humanos a los seres humanos, en qué somos iguales, porque en algo tendríamos que ser iguales (de otro modo no seríamos humanos) y en qué no somos iguales, que es casi en todo, por cierto. Es decir, todos los antropólogos andan en la búsqueda de lo que es común a todos los grupos humanos y nunca nos ponemos de acuerdo. El maestro Lévi Strauss, el gran antropólogo de la segunda mitad del siglo xx (que acredita, por cierto, que los antropólogos, a pesar de que tomen mucho alcohol, pueden ser muy longevos, pues murió a los 101 años, ya en el siglo XXI) propuso que este elemento común es la prohibición universal del incesto, pero no todos le creen. Justamente el mismo Lévi Strauss planteaba que la reflexión antropológica o etnológica tiene tres fuentes históricas funda-

118 mentales, es decir, tres acontecimientos intelectuales que le dan impulso a esta disciplina o ciencia: el descubrimiento del Nuevo Mundo, la Revolución Francesa y la aparición de la teoría de Darwin.

\section{El descubrimiento del Nuevo Mundo}

Adrede uso las palabras "Nuevo Mundo" que no aplican para nosotros porque, en sentido estricto, no descubrimos nada, porque aquí estaban los que aquí habitaban. Ya estaban bastante descubiertos, en el sentido de que ya se conocían a sí mismos, y además estaban muy descubiertos porque usaban poca ropa. El Nuevo Mundo es para los que llegaron, porque los que ya estaban aquí ya sabían que esto existía. Pero el descubrimiento del Nuevo Mundo, o de América, o como le quieran llamar ustedes, representó para Occidente (en el ambiente intelectual de una 
Europa en la que se desarrollaba al mismo tiempo el Renacimiento, la Reforma Protestante y en ese sentido también el humanismo) precisamente la pregunta sobre el ser humano. ¿Quiénes son esos que están ahí? ¿Son changos? ¿Son animales? ¿Son peces del demonio? Sobre todo, porque Occidente sabía que había distintas formas de ser, otros fenotipos: conocían a los de la India, a los chinos, algo había platicado Marco Polo de los de Cipango (japoneses), y de los árabes, los hotentotes y los africanos negros, en fin... pero cuando llegaron a América ya no bastó una respuesta bíblica, sino que había que preguntarse por la condición de estos seres. En este sentido, para Lévi Strauss se trata del primer impulso de la pregunta por el ser humano, pero sobre todo la necesidad de empezar a frasearlo ya no en una versión puramente teológica, sino justamente en una versión humanista que después dio lugar a esta pretensión científica de la antropología.

\section{La Revolución Francesa}

Dice Lévi Strauss que la Revolución Francesa le mostró a Occidente que no solo hay otros fuera de Occidente sino que se puede ser de otra manera. Es decir, se trata de la pregunta por el otro, pero no el otro que está en otro lado, sino el otro que está en otro tiempo, y entonces se plantea durante la Revolución Francesa la pregunta por la alteridad que existe en uno mismo, un poco el propio que decía Octavio Paz.

\section{El origen de las especies}

Y el último acontecimiento, continua Lévi Strauss, es la publicación de El origen de las especies de Darwin, a mediados del siglo XIX, porque la propuesta darwiniana permite explicar científicamente, es decir, buscar una explicación objetiva de la diversidad de las especies. A continuación aparecieron pensadores sociales que afirmaban que la idea de la diversidad de las sociedades también puede explicarse desde la perspectiva de la evolución. No en vano la primera corriente teórica de la antropología 
fue justamente el evolucionismo, en dos vertientes: una que se conectó con el planteamiento positivista spenceriano y la vertiente de Morgan, que fue adoptada inmediatamente por Marx y Engels. De hecho, el libro de Engels, El origen de la familia, la propiedad privada y el Estado, es una copia de Morgan (en esa época no había tanto problema con los plagios, pero es un fusil. Además, abierto y descarado, porque Engels nunca niega que lo que escribió sea un resumen de La sociedad primitiva de Lewis H. Morgan, prácticamente él mismo dice que "todo estaba en el texto de Morgan", o sea que él no sabía mucho de lo que ocurría, por ejemplo, en Norteamérica o en otros pueblos alejados de su mundo que era Inglaterra; si acaso, sabía algo de Alemania por Marx).

El evolucionismo plantea que podemos dar una explicación objetiva a la diversidad de los grupos humanos, una explicación objetiva a la diversidad de la especie humana. El propio planteamiento enseña que las razas, incluidas las humanas, se forman en un proceso evolutivo. Eso permite entender por qué los evolucionistas creían que había razas inferiores y superiores. O bien, como Morgan da a entender, que hay estados por los que tiene que pasar toda sociedad, con los cuales puede establecerse una gradación de las sociedades. Morgan clasifica las fases de evolución de la sociedad humana en tres grandes periodos: el salvajismo, la barbarie y la civilización. Cada una tiene, a su vez, una fase inferior, media y superior, y así se describe toda una serie de indicadores para definir cada periodo. Por ejemplo, si ustedes quieren saberlo, los aztecas están clasificados por Morgan en la etapa dos de la barbarie, porque no tenían elementos de las siguientes etapas, como el uso de la rueda. Morgan creía que no había escritura, no percibía la existencia propiamente de un Estado y por eso los clasificó así.

Esa era la idea, se trataba de clasificar. Así como Lineo clasificaba a las especies, también se podían clasificar las sociedades en una gradación evolutiva, según los avances de la cultura material, los dispositivos tecnológicos. En ese punto se conectan Marx y Morgan, porque Marx le da una importancia fundamental al desarrollo de las fuerzas productivas y Morgan también lo creía. Para Morgan, la cerámica, la agricultura y después la formación de ciudades son grandes revoluciones, 
tecnológicas o sociales, que permiten entender cómo evoluciona la sociedad. La escritura también lo es, así como el uso del hierro y el acero, etcétera, un largo etcétera.

\section{Preocupaciones de la antropología}

Así pues, yo plantearía que la antropología, de entrada, enfrenta tres preocupaciones y posee tres características que también aparecen desde su inicio. En primer lugar, está ligada a los procesos de dominación colonial. No en balde los grandes antropólogos clásicos están vinculados a instituciones que representan claramente a los imperios colonialistas. Los grandes antropólogos fundacionales son ingleses, alemanes, franceses o estadounidenses, o no ingleses, pero que trabajaron en Inglaterra. Por ejemplo, el polaco Bronislaw Malinowski, que estudió a los habitantes de las islas Trobriand de Nueva Guinea y es uno de los grandes clásicos, está claramente inserto en instituciones británicas, aunque procediera del Imperio Austrohúngaro. Malinowski plantea un tema muy interesante respecto de la dominación colonial, pues dice que la antropología le va a permitir al Imperio Británico pasar de lo que se llamaba entonces el direct goverment, es decir, el "gobierno directo" al indirect group. Dice Malinowski que los antropólogos le pueden demostrar al Imperio Británico que es mejor, más tranquilo, más viable, que los pueblos que están dominados por la Corona británica se gobiernen a sí mismos, claro, nada más que educados por Inglaterra, pero que no es muy agradable que tengan los hindúes o indios un virrey, mejor que tengan su propio gobierno; en África, sobre todo, vamos a buscar el indirect group. Esto deja muy claro cuál es el papel y el estrecho vínculo que tiene la antropología con el contexto y los proyectos coloniales y después también neocoloniales. Si alguien aprendió la vigencia del indirect group fue el imperialismo estadounidense, al cual no le gustó poner gobiernos con gringos, sino establecer gobiernos locales en cada una de esas sociedades, naciones o pueblos, pero que obedecieran siempre a sus intereses. Como ejemplo, recordemos el pacto de la embajada que permitió el asesinato 
de Madero y la usurpación de Victoriano Huerta. Bueno, ahí no hubo antropólogos, pero sí necesitaban un gobierno títere.

En segundo lugar, digamos que otro asunto que la antropología aborda desde un principio es su confrontación o su preocupación por la diversidad de la especie y de los grupos humanos. De hecho, desde un inicio, pero sobre todo ya cuando se configuró el proyecto culturalista de la antropología estadounidense, que luego heredó la Escuela Nacional de Antropología e Historia, surgió como un programa sustentado principalmente en cuatro grandes pilares. El primero es la antropología fisica o biología humana, que se hace cargo de la diversidad de la especie como tal, desde el punto de vista físico, biológico. Por ejemplo, la antropología física o biología humana ocupó buena parte del siglo xx para discutir si había o no razas, hasta que hacia la década de 1960, después de la Segunda Guerra Mundial y de las experiencias nazis, llegó a la conclusión de que no hay razas en la especie homo sapiens, sino solo una variante racial que es la homo sapiens sapiens; lo demás son diferencias fenotípicas que pueden ser más o menos discretas, más o menos recurrentes, pero que no constituyen la idea de raza. Esto es parte de la reflexión antropológica particularmente en la escuela estadounidense, porque en otras escuelas, la antropología física la van ustedes a encontrar en los

122 departamentos de medicina o de biología, ciencias de la salud o ciencias médicas. El segundo pilar es la arqueología, que tiene que ver con el reconocimiento y estudio de sociedades desaparecidas a través de sus vestigios materiales, y que también, por ejemplo en Inglaterra, se encuentra en los departamentos de historia, mientras que en Estados Unidos formó parte del programa de esta antropología holística o integral. En México, la arqueología es fundamental como vamos a ver más adelante. El tercer pilar de esta antropología holística o integradora es la lingüística, pues evidentemente la diversidad lingüística es muy importante para entender a los grupos humanos, para entender esta diversidad de la especie. Finalmente, la antropología social o etnología estudia las distintas formas de organización de los grupos o sociedades humanas.

Otro elemento importante de la antropología es que siempre está confrontada con otros universos culturales, y hablo de universos culturales porque es tan difícil entender sociedades distintas, que la antro- 
pología, a diferencia de las ciencias que se hicieron para estudiar la sociedad moderna, no puede hacer un estudio para parcializar, entre otras cosas porque estas parcelas que inventó Occidente para estudiarse: economía, política, si ustedes quieren religión, arte, estética, administración, no operan en las sociedades no occidentales. Por ejemplo, cuando un pueblo para sembrar necesita primero hacer un listón de petición y luego enterrar unas ofrendas en los cuatro rumbos de la parcela, ¿eso es economía o es religión? Hasta en las propias sociedades premodernas occidentales, por ejemplo, en el virreinato de la Nueva España, ¿en qué medida hay arte o religión en las pinturas que decoran las iglesias? Estas separaciones no operan. Por eso, la antropología, de entrada, tiene que acercarse a estas sociedades otras como universos culturales para entender: yo no puedo entender nada más un pedazo, tengo que entender el conjunto.

\section{Debates actuales en la antropología}

Un aspecto más que me parece importante destacar de la antropología es cómo, desde el principio, se produjo un debate que sigue presente: los evolucionistas proponen que las sociedades se agrupan en una especie de ley o dependencia universal que todas tienen que seguir, y por eso es posible ordenarlas. Pero inmediatamente se le enfrentó el particularismo histórico (los historiadores algo sabrán: por ejemplo, Dilthey), para el cual eso no opera en las sociedades humanas, pues cada sociedad tiene su propia vertiente de desarrollo y es absurdo pensar en teorías con leyes generales. Esta discusión sigue presente, con dos principios generales que la articulan y que son aceptados, digamos, en la antropología contemporánea: que todos los pueblos tienen cultura y que no hay culturas superiores e inferiores. Así, todos los pueblos o sociedades tienen un cultura, y si no tuvieran, no podrían los evolucionistas y neoevolucionistas trazar una evolución cultural. En la antropología no existe gente inculta, no existen sociedades incultas; puede haber falta de instrucción, puede haber gente torpe, puede haber gente que no ha leído muchos libros, citando a algún clásico, pero forma parte de un 
universo cultural. Tal es el principio universalista de la cultura en la antropología.

El otro principio, que puede discutirse más, pero que en general ya es aceptado en todas las tendencias antropológicas, es que no hay culturas inferiores ni superiores, solo distintas. En general ya nadie, ni los neoevolucionistas, piensan que haya algo inferior o superior. Se trata de distintas líneas de desarrollo, distintas maneras que tienen los grupos humanos de resolver el problema de la sobrevivencia, de la convivencia y de la organización.

Con esos principios, la antropología sigue en la discusión no solo de esta deriva universalista o particularista, sino también y fundamentalmente de qué clase de ciencia es la antropología. Hasta el estructuralista Lévi Strauss (aunque casi ya no hay estructuralistas) pensaba que la antropología es una ciencia que hace leyes, explicaciones o teorías generales. Lévy Strauss quería entender las estructuras del pensamiento salvaje, las estructuras del parentesco, y eso aplica para todos. Por eso pensaba que la mejor manera de hacer antropología es seguir el modelo de la lingüística estructural, que muestra que todas las lenguas tienen una estructura semejante. Todas las lenguas tienen estructuras fonéticas, morfológicas, sintácticas, gramaticales, discursivas. Obviamente, también aquí aplica que no hay lenguas superiores ni inferiores, solo diferentes. En cualquier lengua se puede decir cualquier cosa, siempre de diferente forma. Entonces, lo que Lévy Strauss buscaba son esas estructuras, semejantes a las estructuras lingüísticas, que ordenan el pensamiento y el quehacer humano.

Entre tanto, hay muchas posturas que dicen "no, no, la antropología no pretende eso, la antropología es una ciencia que busca significado o interpretaciones". En la discusión sobre filosofía de la ciencia se le llama a las primeras ciencias nomotéticas, porque proponen leyes, teorías generales, y a las otras, ideográficas, porque simplemente describen fenómenos, o si ustedes quieren, serían disciplinas fenomenológicas como la historia. La historia es claramente una ciencia ideográfica, fenomenológica, es decir, busca las características particulares del fenómeno, busca claves de interpretación. También se podría decir que es, en ese 
sentido, una disciplina o ciencia hermenéutica: lo que busca es el significando de esto que ocurre, esto que la gente dice o hace.

Me gustaría también que reconociéramos que la antropología es desde un principio y en este encuentro con el otro, una ciencia o una disciplina ambivalente, en el sentido de que va de la mano del colonialismo, pero también contribuye decisivamente a la crítica cultural de Occidente, como dicen algunos autores. Es decir, los antropólogos en general, incluido Malinowski que hablaba del paso al indirect group, han encontrado también en la diversidad de los pueblos otros una crítica de lo propio, un poco al estilo, si ustedes quieren (no me lo tomen como una proclama de ninguna especie), de lo que dicen los zapatistas: "hay otros mundos posibles". Eso no lo inventó el subcomandante Marcos, la antropología sabe desde su aparición e incluso desde sus antecedentes, como los frailes misioneros, que hay otros mundos posibles, y si hay otros mundos posibles, entonces, desde los frailes misioneros en América, también pueden ser utopías posibles. Puede haber mundos en donde lo que prevalece, por ejemplo, es el principio de la utilidad o el principio del intercambio. Marcel Mauss, sobrino de Emilio Durkheim, afirmaba que hay sociedades en las que lo que prevalece es el principio del don, es decir, yo te doy, tú devuelves y yo reciproco: dar, recibir, devolver, y ahí tenemos la muestra de que la economía de mercado existe, pero no es la única, aunque mis compañeros neoliberales piensen que sí, que no hay otra manera de organizar el mundo. Sí, sí hay otras, por supuesto. Por eso la antropología ha contribuido decisivamente a esto que podríamos llamar la crítica cultural de Occidente. En este sentido, dice Geertz que la antropología amplía el universo del discurso humano, conjura el miedo y la desconfianza hacia el otro. Es decir, mi encuentro con el otro puede ser "tú hazle como yo". Recuerdo que de niño me enseñaron que nosotros éramos un país subdesarrollado y que íbamos a ser desarrollados y a ser como Estados Unidos, lo que pasa es que ahora estamos como niños, pero después vamos a ser adultos iguales. Esa teoría desarrollista creo que ya pasó, aunque sigue presentándose de alguna manera en ciertos esquemas que nos quieren mostrar a los países que ahora se les llama periféricos o emergentes. 
En este sentido, la antropología se debate entre dos propuestas, en el estudio de las sociedades distintas, otras: aculturación e interculturalidad. Gonzalo Aguirre Beltrán, cuando plantea lo que debe ser el indigenismo, lo define como una aculturación planificada: el tema es cómo lograr que los pueblos indígenas se inserten en la modernidad. Es lo que hacían, sin ser antropólogos, los frailes evangelizadores, y lo hacían a veces muy bien y también tenían que estudiar y cuidarse de muchas cosas; por ejemplo, lo primero que obligaban a los frailes era a aprender las lenguas. Fray Junípero sabía pame, algo de otomí y algo de náhuatl, y por eso algunos estudiosos de la antropología en México dicen que los frailes eran antropólogos. Yo digo que eran frailes, pues supongo que los antropólogos son profesionistas que estudiaron antropología. Pero ciertamente, si uno ve los trabajos de fray Bernardino de Sahagún, cualquier antropólogo quisiera tener una obra de esa envergadura.

Por otro lado, está la deriva de lo que podríamos llamar la interculturalidad, es decir, el reconocimiento de que somos diferentes y tenemos que establecer una relación de igualdad, de reconocimiento recíproco, de comprensión para encontrar espacios (lo que no siempre es sencillo) de diálogo e intercambio. No siempre es sencillo, porque de suyo, cuando se enfrentan dos maneras de vivir y de pensar el mundo, se enfrentan dos esquemas de valores, y entonces se debe determinar sobre qué esquema se va a definir la relación. Por eso, en nuestro país no es sencillo siempre encontrar ese espacio (que a veces se le puede llamar "derechos humanos") en el cual se encuentran universos culturales distintos. A veces sí, efectivamente, existe un problema de derechos humanos, pero a veces también puede haber un problema de incomprensión. Yo, por ejemplo, no me atrevo a pontificar sobre el caso de la señora Nestora y las policías comunitarias de Olinalá. No es sencillo entender hasta dónde hay diferencias, el tratamiento que da una sociedad u otra a las infracciones, las trasgresiones, los delitos, pues también en cualquier sociedad puede haber excesos, tropelías y atropellos de toda índole.

También por el hecho de que la antropología es como un ejercicio de encuentro con universos culturales distintos, tiene que echar mano de 
una herramienta, digamos de una fuente de información, una herramienta metodológica que no puede apoyarse solo y principalmente en fuentes documentales o indirectas. Los sociólogos, por ejemplo, a veces se apoyan en una encuesta, un estudio de opinión, y también los antropólogos, pero la herramienta básica de la antropología, precisamente porque aquí no se trata de plantear una pregunta y hacer una gráfica, es la etnografía, la etnografía en el sentido de vivir con el otro. Antes eran grandes travesías. Malinowski fue hasta las Islas Trobriand y hacía meses de travesía y se quedaba ahí también meses en su campamento y luego de nuevo a Inglaterra a escribir, o a reescribir, porque la etnografía te marca el requisito de que escribas todos los días. Yo, por ejemplo, ahora quiero hacer etnografía del funcionariado público, pues tengo muchas experiencias (tengo relación con todos los funcionarios del gobierno federal, muchos estatales, muchos municipales, pues he ido a recorridos con el presidente y los secretarios de gobierno en las zonas afectadas por el terremoto). La única falla es que no puedo escribir todos los días; vivo la experiencia pero me falta el diario de campo. Algún día, si mi memoria me lo permite, lo procuraré hacer.

La etnografía, pues, es la herramienta fundamental de la antropología, ya que se sustenta en el trabajo de campo y la experiencia, yo diría: la experiencia del otro. En la antropología es muy bien vista, porque de lo que se trata es de construir una interpretación o explicación - lo que uno quiera hacer - a partir de lo vivido, no de lo platicado. Es grave que yo argumente diciendo que como Malinowsky hizo y dijo, entonces yo hago y digo. No. En general, en la antropología la etnografía es la fuente directa, fundamental. Así como los historiadores buscan el documento original y no documentos que son fuentes indirectas, aquí lo que busca el antropólogo es la experiencia directa, o como dirían algunos manuales de etnografía, estar ahí. Incluso hay una discusión ahora sobre qué es hacer etnografía en la red. Una vez se hizo un estudio de personas transgénero y la principal herramienta etnográfica fue Facebook. Luego se descubrió que no bastaba y se tuvo que buscar el contacto directo con las personas, pero la herramienta de Facebook fue fundamental. Y desde hace muchos años se acabó la idea de que la etnografía 
implica hacer un viaje larguísimo, ir a quién sabe dónde, al África; pero sí es muy importante la etnografía como vivencia. El propio lingüista lo tiene muy claro, por eso también es frecuente que la antropología recomiende las etimologías cuando se va a trabajar con indígenas y hay que aprender la lengua. Es otro tache que yo tengo. He trabajado sobre todo con poblaciones ñäñho (otomíes) y entiendo palabras, pero no sé hablar la lengua, no la entiendo de corrido, y sin embargo es necesaria, porque hay que desmenuzar cuáles son las formas de comprensión y cultura que puede tener un grupo (regreso a la idea de un universo culturalista).

Quisiera, para terminar, ir a la parte de la antropología en México. Así como la antropología europea es hija del colonialismo, la antropología en México es hija de la Revolución Mexicana. Antes no había propiamente antropología. Apenas en los últimos años de Porfirio Díaz se abrió una simpática escuela que se llamaba Escuela de Arqueología y Etnología Americanas, que fundó Edward Seler, un antropólogo alemán importantísimo, que también era cercano a Franz Boas, el gran impulsor del relativismo cultural y del culturalismo en Estados Unidos. Había la idea de establecer una escuela para empezar a fomentar los estudios arqueológicos y etnológicos en América. Otra vez arqueología y etnología. El primer antropólogo que surgió de esa escuela, que después dirigió, fue Manuel Gamio. Su primera publicación, en 1916, tiene un nombre prístino, Forjando patria, y si ustedes ven la presentación, hay una metáfora metalúrgica muy propia de esas ideas positivistas, pues la forja de la patria incluía la fusión del bronce indígena amerindio con el hierro europeo, y termina con algo así: “Ahí está la forja y el antropólogo golpea". Todo un programa intelectual para la antropología: forjar la patria. La preocupación central de su obra es cómo vamos a incorporar a la forja de la patria a esas pequeñas secciones indígenas que no se sienten parte de México. Es la preocupación que ya había expresado Andrés Molina Enríquez, que no era antropólogo, no tan bonito como Manuel Gamio, pero lo afirmó en Los grandes problemas de la nación. La idea de la antropología posrevolucionaria es integrar e incorporar a los pueblos indígenas a la conformación de esta patria que emerge del 
gran proceso histórico violento, catastrófico, sísmico, que fue la Revolución Mexicana. La antropología buscó integrar a los pueblos indígenas. Y tal integración iba desde recuperar las grandes raíces de las civilizaciones prehispánicas, hasta sumar a los pueblos indígenas de entonces al progreso nacional.

No era un tema de desprecio, no era un tema de desconocimiento. Era un tema de incorporación, de integración en una idea que yo llamaría monocultural de México. Todavía en la primera mitad del siglo xx o, si se quiere, hasta la séptima década, la idea que se tiene de México como proyecto de nación, y por lo tanto la que tienen los antropólogos, es construir una nación unificada en lo político, económico, social, cultural. Todavía esa idea ilustrada, si ustedes quieren, de nación o de Estado nación, entendido este concepto como una lengua, una cultura, una ley y en algunos casos, aunque no del siglo XIX, una religión.

De eso se trató el indigenismo. El indigenismo fue el programa aplicado de la Revolución Mexicana hasta la década de 1980. Se quiso integrar a los pueblos indígenas en esta idea de una nación, a la que claro que los indígenas iban a aportar, pero no se podía aportar mucho en un país unitario, una nación unitaria.

Esto empezó a cambiar radicalmente en la década de 1980, y sobre todo en la de 1990, por fenómenos que tienen que ver con México, pero también con el entorno mundial. Más o menos desde la caída del bloque soviético se fracturaron las grandes teorías o los grandes paradigmas de la ciencia social, que eran el funcionalismo, el marxismo y el estructuralismo. Ya no está muy de moda pensar en que hay teorías totales de la sociedad. Del estructuralismo se deriva, por ejemplo, el posestructuralismo de Derrida, Foucault, Lyotard y otros autores franceses que partieron de la postura vive la difference! Si ustedes ven el discurso de toma de posesión de Vicente Fox, yo no sé quién lo hizo, pero es un elogio de la diversidad. En la primera foto presidencial había aquí de todo: gente en silla de ruedas, prietos, blancos, señoras, gorditos... se proyectaba la idea de que ahora sí vamos a ser un país diverso, sabroso. También había problemas tan complicados como el alzamiento del EZLN en Chiapas, que primero tenía un discurso de guerrilla foquista de la década de 1960: 
vamos a ir a Palacio Nacional a tomar el poder y hacer un país socialista proletario. Más o menos eso es lo que dicen al principio, pero se dieron cuenta de que eso no iba a ir a ningún lado, y a los 15 días el discurso ya era de un mundo en el que cupieran muchos mundos. Darle voz a los sin voz, los indígenas... Empiezan a cobrar conciencia de que se trata de reivindicar la diversidad.

Antes de eso hay una discusión muy complicada a propósito de los 500 años del descubrimiento de América: a los 500 años de la llegada de Cristóbal Colón surgió el programa Encuentro de dos mundos y, al mismo tiempo, un movimiento que se llamaba Quinientos años de resistencia indígena, negra y popular, y la cosa se ponía difícil, pues estos programas se fortalecieron. Ahora ya no es que vinieron a darse la vuelta con unos barcos, ahora es que se bajaron, se metieron, cayó Tenochtitlan. Surgieron entonces las interpretaciones fundamentales del lado español y del lado, si ustedes quieren, mexica. Este fundamentalismo azteca no se da cuenta de que aquí no había un país, sino un montón de pueblos, muchos de ellos muy confrontados entre sí.

A lo que voy es a que, hacia el final del siglo pasado, ya no era tan aceptable la idea de un país unitario, de una nación unicultural. De hecho, en Bolivia incluso ya instauraron lo que ellos llaman un estado multinacional. Aquí no, aquí desde 1992 el país se define de una manera distinta. Antes en el artículo $4^{\circ}$, ahora en el artículo $2^{\circ}$ de la Constitución se dice que México es una nación pluricultural cuya condición se sustenta originariamente en sus pueblos indígenas; es multicultural. Esto que parece simplemente un detalle simpático de algún diputado ingenioso, es en realidad cambiar el proyecto de la nación; que todavía esto no sea más que una frase de la Constitución es real, pero es el rencuentro de la nación. Ahora, por ejemplo, no hay una lengua nacional, como a mí me enseñaron en la primaria; es más: no hay lenguas nacionales, sino que todas las lenguas indígenas y el español son lenguas oficiales de México y ninguna oficialmente es más o menos que otra. Eso es lo que dice la Ley de Derechos Lingüísticos. En realidad, hay todavía una enorme discriminación, pero a lo que voy es que hacia finales del siglo xx se pasó de una decisión unicultural a una perspectiva 
pluricultural de la nación, y esto supone para la antropología y, porque no, para las ciencias sociales y aun para la reflexión humanista en México, pensar de otra manera, pensar en cómo podemos documentar, reconocer y además construir espacios de diálogo entre los distintos universos culturales que existen en nuestro país. No es un tema de números simplemente, es un tema de si reconocemos esta diversidad como una riqueza y cómo la habilitamos para encontrar salidas a la problemática nacional. Yo recuerdo que alguna vez en Querétaro, cuando llegaban a aplicarse en estos temas diversos criterios estadísticos, el gobernador me preguntó que qué caso tenía ponerse a discutir una ley de derechos y cultura de los pueblos indígenas si los hablantes de lengua indígena en Querétaro son solo el 1.8\% de la población. En otro encuentro dije que, con ese criterio, Querétaro tendría que pasarse a un municipio de Guanajuato, porque Querétaro tiene el 1.6\% de la población nacional. ¿Para qué va a ser un estado libre y soberano? (Por cierto: Querétaro es estado libre y soberano desde la primera Constitución Federal de México de 1824, gracias a un cura que se llamaba Félix Osores Sotomayor, que dijo, en un discurso impecable, que desde el punto de vista histórico, simbólico, espiritual y religioso, Querétaro debería ser distinto, un estado diferente, pues se lo estaban repartiendo entre Guanajuato y San Luis Potosí. Si no es por ese hombre, Querétaro sería hoy municipio de Guanajuato.)

Yo creo que esta cuestión del pluralismo nos tiene que llevar a una discusión compleja, que, insisto, atraviesa las distintas disciplinas, incluidas las que se estudian en el Departamento Académico de Estudios Generales del ITAM, porque si nosotros reconocemos verdaderamente la condición plural de México, entonces tenemos que entrar al terreno de cómo podemos reconocer en los pueblos distintos un pluralismo epistemológico, es decir, que la gente conoce las cosas de distinta forma. Este pluralismo epistemológico está vinculado al pluralismo lingüístico: en el país hay 68 grupos lingüísticos, y si tomamos en cuenta las variantes lingüísticas de estos 68 grupos, hay 364 variantes, y si agregamos el español (y cabría también la posibilidad de sumar sus variantes) ya son 365. Podríamos tener una lengua para cada día del año. 
Por otro lado, ahora en la antropología se discute mucho la noción, por ejemplo, del pluralismo axiológico o de los valores, es decir, cómo en las sociedades indígenas puede haber valores diferentes. No hablamos de valores superiores o inferiores, sino diferentes, y de valores que también se transforman. Por ejemplo, he visto feministas digamos, mestizas, ese término ya cada vez se usa menos, mestizas y mexicanas estándar, que dicen que los pueblos indígenas son muy machistas, y puede que en algo tengan razón. Pero también he visto que en los pueblos indígenas hay una lucha de las mujeres por cambiar la correlación de fuerzas. Cuando con facilidad decimos que los árabes son machistas, digo ¿y cómo éramos hace 20 años? Quizá entonces, ellos también cambiarán. Y ahora se discute también un ámbito fuerte, que es el tema del pluralismo jurídico. Ya poco se utiliza en antropología el concepto de usos y costumbres, porque usos y costumbres hay en cualquier parte; más bien se discute sobre los sistemas normativos alternativos o indígenas. Y vaya que sí hay sistemas distintos. Simplemente les quiero referir un documento que a mí me conmovió: es una carta que dirige una comunidad otomí a finales del siglo xIX al gobernador de Querétaro, Francisco González de Cosío, la cual empieza diciendo "nos dirigimos a usted como a un dios" y termina: "y lo único que queremos pedirle señor Gobernador es que no nos quite a nuestro juez indígena”. O sea, no pedían dinero, ni programa oportunidades ni nada de eso. Nomás que dejaran al juez.

Me sorprendió mucho una experiencia vivida en Santiago Mexquititlán, una comunidad otomí que exporta mucha gente. Ahí viven como 9000 personas, pero fuera de Santiago y que reconocen a Santiago como su pueblo, debe haber unas 3500 más en Querétaro, Ciudad Nezahualcóyotl, la colonia Roma, Mazatlán, Guadalajara, Monterrey, San Luis Potosí y ahora también en poblaciones de California. Un día estaba por ahí en el pueblo y conocí dos familias que venían de San Luis Potosí. Allá viven, pero vinieron porque preferían dirimir aquí ciertas diferencias que tenían sobre los linderos de sus terrenos en San Luis Potosí, y prefirieron ir con el juez de paz de su pueblo en Querétaro, súper lejos, porque a él sí le tenían confianza de lo que decidiera. 
Ahora mismo también se discute en antropología lo que representa el pluralismo ontológico, es decir, si partimos de que el mundo existe porque lo construimos conceptualmente, si no, no habría algo así como mundo (por eso dice Jean Piaget que en realidad uno no sabe lo que ve, sino que uno ve lo que sabe). O sea que si no tuviéramos conceptos, palabras, nociones para ordenar lo que percibimos sensorialmente, probablemente nomás serían sensaciones muy desorganizadas. En realidad, el mundo es distinto no solo en la lengua, no solo en la manera de ver, sino el mundo mismo, y eso nos lleva a discusiones más complejas.

Creo, pues, que es muy importante que la antropología aparezca en un programa de formación humanista para los estudiantes del ITAM, para los estudiantes de las ciencias administrativas, económicas, políticas y jurídicas, porque creo que es fundamental incorporar este componente de pluralidad, del encuentro con los otros y de la antropología como esa disciplina que nos abre la posibilidad de construir espacios de diálogo entre los diferentes. 
Se prohíbe su reproducción total o parcial por cualquier medio, incluido electrónico, sin permiso previo y por escrito de los editores. 